\title{
Supramolecular Porphyrin-Based Metal-Organic Frameworks with Fullerenes: Crystal Structures and Preferential Intercalation of $\mathbf{C}_{70}$
}

\author{
Tetsushi Ohmura, ${ }^{*[a]}$ Arimitsu Usuki, ${ }^{[a]}$ Yusuke Mukae ${ }^{[a]}$ Hirofumi Motegi, ${ }^{[a]}$ Shuji Kajiya, ${ }^{[a]}$ \\ Masami Yamamoto, ${ }^{[a]}$ Shunsuke Senda, ${ }^{[b]}$ Tsuyoshi Matsumoto, ${ }^{[c]}$ and Kazuyuki Tatsumi ${ }^{[b]}$
}

\begin{abstract}
The syntheses and characterization of two new porphyrin-based metal-organic frameworks (P-MOFs), through the complexation of 5,10,15,20-tetra-4-pyridyl$21 \mathrm{H}, 23 \mathrm{H}$-porphine $\left(\mathrm{H}_{2} \mathrm{TPy}\right)$ and copper(II) acetate (CuAcO) in the presence of the fullerenes $\mathrm{C}_{60}$ or $\mathrm{C}_{70}$ are reported. Complex 1 was synthesized in conjunction with $\mathrm{C}_{60}$, and this reaction produced a two-dimensional (2D) porous structure with the composition CuAcO-CuTPyP $\supset m$-dichlorobenzene $\left(m\right.$-DCB), in which $C_{60}$ molecules were not intercalated. Complex $\mathbf{2}$ was synthesized in the presence of $\mathrm{C}_{70}$, generating a three-dimensional (3D) porous structure, in which $C_{70}$ was intercalated, with the composition CuAcO-CuTPyP. $\mathrm{C}_{70} \supset m$-DCB. $\mathrm{CHCl}_{3}$. The structures of these materials were determined by X-ray diffraction to identify the supramolecular interactions that lead to $2 \mathrm{D}$ and $3 \mathrm{D}$ crystal packing motifs. When a combination of $C_{60}$ and $C_{70}$ was employed, $C_{70}$ was found to be preferentially intercalated between the porphyrins.
\end{abstract}

When synthesizing porous materials using paddle wheel-type clusters, it is helpful to take advantage of accurate configuration control of active sites when anticipating applications in gas storage and catalysis, based on various combinations of transition metals and substituted organic ligands. These porous materials may be classified as zero-, one-, two- or three-dimensional (0-, 1-, 2- or 3D) structures. ${ }^{[1]}$ By using pyrazine derivatives as pillar ligands and tetrakis(4-pyridyl)cyclobutane it is possible to form bridges between these paddle

[a] Dr. T. Ohmura, Dr. A. Usuki, Y. Mukae, Dr. H. Motegi, S. Kajiya, M. Yamamoto

Toyota Central R\&D Labs., Inc

41-1, Yokomichi, Nagakute, Aichi 480-1192 (Japan)

E-mail:e1314@mosk.tytlabs.co.jp

[b] Dr. S. Senda, Prof. K. Tatsumi

Research Center for Materials Science

Nagoya University

Furo-cho, Chikusa-ku, Nagoya, Aichi 464-8602 (Japan)

[c] Prof. T. Matsumoto

Institute of Transformative Bio-Molecules (WPI-ITbM)

Nagoya University

Furo-cho, Chikusa-ku, Nagoya, Aichi 464-8601 (Japan)

$\square$ Supporting information for this article can be found under http:// dx.doi.org/10.1002/asia.201501422. wheel clusters, thus fabricating porous 1-, 2- or 3D structures. ${ }^{[1 a, 2]}$

One of the most versatile components for the construction of porphyrin-based metal-organic frameworks (P-MOFs) is $\mathrm{H}_{2}$ TPyP. In this compound, the porphyrin moiety is fully functionalized with four pyridyl groups and thus acts as a planar tetratopic donor. The tetragonal orientation of the peripheral pyridine ligands allows the formation of infinite parallel sheets with lattice structures, in which the four pyridyl groups are linked together by transition metal ions. ${ }^{[3]}$ Recently, we reported the first example of a porous P-MOF comprised of $\mathrm{H}_{2}$ TPyP as a four-connected vertex and $\mathrm{CuACO}$ as a linear linker motif, forming a regular 2D coordination network. ${ }^{[3 d]}$ As the $2 \mathrm{D}$ sheets in this material do not interpenetrate, the channels that run through the structure can be used for gas absorption when the P-MOF is evacuated. Some P-MOFs have very interesting properties that suggest potential applications, such as hydrogen storage, ${ }^{[2 b, 4]}$ selective sorption of guest molecules, ${ }^{[5]}$ and heterogeneous catalysis. ${ }^{[6]}$

As is well known, the tetragonal shapes of porphyrins and the sphere/ellipse shapes of fullerenes lead to self-assembling supramolecular structures. ${ }^{[7]}$ Sun et al. reported the crystal structure of MOF-C ${ }_{60}$, formulated empirically as $\mathrm{H}_{2}$ TPyP.Pb $\left(\mathrm{NO}_{3}\right)_{2} \cdot \mathrm{C}_{60} \cdot 1.5$ TCE (TCE $=1,1,2,2$-tetrachloroethane) has $52 \%$ free volume calculated by van der Waals surfaces. ${ }^{[7 a]}$ We therefore developed a strategy in which $C_{70}$ fullerene pillars and a paddlewheel linker were used to construct P-MOFs, increasing the potential of these materials to act as "organic zeolites". The features of these synthesized P-MOFs are $2.2 \mathrm{~nm}$ wide square-grid. In this study, we report the syntheses and characterization of two new P-MOFs, potentially incorporating the fullerenes $C_{60}$ and $C_{70}$.

The reaction of $\mathrm{H}_{2}$ TPyP, CuAcO, and $\mathrm{C}_{60}$ produced reddishbrown crystals of 1 but without intercalation of $\mathrm{C}_{60}$ between the porphyrins. As shown in Scheme 1, the $\mathrm{H}_{2}$ TPyP is tetragonally connected by $\mathrm{CuAcO}$ in an infinite $2 \mathrm{D}$ sheet structure with $2.2 \mathrm{~nm}$ square-grid. This motif is very similar to that found in non-fullerene P-MOFs. ${ }^{[3 \mathrm{~d}]}$ In contrast, a combination of $\mathrm{H}_{2}$ TPyP, CuAcO, and $\mathrm{C}_{70}$ generated dark brown crystals of $\mathbf{2}$ in which, to our surprise, $C_{70}$ was intercalated between the porphyrins. In this material, the $2 \mathrm{D}$ sheets formed by the $\mathrm{CuAcO}$ and CuTPyP tend to intercalate $C_{70}$ molecules in an infinite $3 D$ pillared structure.

The structures of $\mathbf{1}$ and $\mathbf{2}$ were confirmed by single-crystal X-ray diffraction (XRD, see the Experimental section and Sup- 


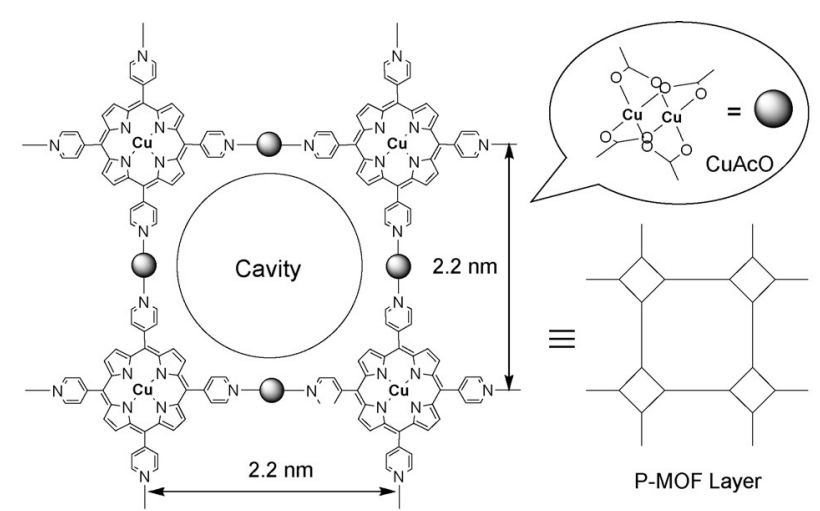

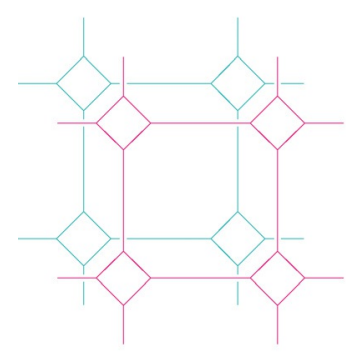

$1(2-D)$

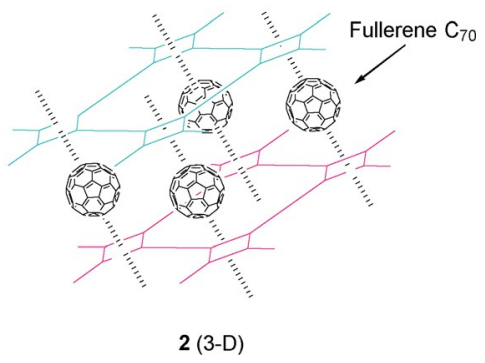

$2(3-D)$
Scheme 1. Construction of P-MOFs incorporating cavities.

porting Information). XRD data demonstrated the lack of covalent bonding between the porphyrin components and the $C_{70}$, although the separation between these units is shorter than expected based on typical van der Waals forces.

The molecular packing motif of $\mathbf{1}$ is shown in Figure $1 \mathrm{a}$. Here, 1D slip-stacked porphyrin chains are interconnected through weak molecular interactions on each face of the porphyrin moieties. A similar packing motif has been reported for the $\mathrm{Cu}(\mathrm{TPP})(\mathrm{Ph})_{4}$ structure $\left(\mathrm{TPP}=\right.$ tetraphenylporphyrin) ${ }^{[8 \mathrm{~d}]}$ In our previous work, and in the case of 1 , interpenetrated structures were not obtained. In the crystal packing of $1, m$-DCB solvent molecules partially fill the lattice cavities, and the void fraction in the structure, estimated from the ratio of the free volume to the cell volume after the $m$-DCB is released from the $2 \mathrm{D}$ network, is remarkably high at $59.8 \%$, assuming that the structure of the MOF skeleton does not change upon solvent removal. The void fraction is calculated using van der Waals surface method. ${ }^{[7]}$ In addition, the structure contains 1D channels along the $a$ axis (Figure $1 \mathrm{~b}$ ).

The nature of the fullerene $C_{70}$-CuTPyP interaction in the crystal packing of $\mathbf{2}$ is shown in Figure $2 \mathrm{a}$. The $C_{70}$ units are precisely centered over CUTPyP moieties that are oriented along the $c$ axis. Porphyrin-fullerene complexes have exhibited similar structural motifs, forming 1D arrays in which the fullerenes are sandwiched between the porphyrin centers to form linear chains ${ }^{[7,8]}$ or zigzag chains. ${ }^{[9]}$

Each $C_{70}$ is sandwiched between CuTPyP centers that are separated by $12.738(3) \AA$, a value that is shorter than the separation distance of $12.8854(2) \AA$ in $\operatorname{CuTPP}(\mathrm{Ph})_{4}\left(\mathrm{CH}_{3}\right)_{4} \cdot \mathrm{C}_{60}{ }^{\left[{ }^{[8 d]}\right.}$ On one face of each CUTPyP center, two opposing pyridyl groups and pyrrole groups bend toward the $C_{70}$, similar to reports of porphyrin-fullerene structures. ${ }^{[8 d, 10]}$ The distance of $\mathrm{Cu}(\mathrm{CuT}$ PyP)... $C\left(C_{70}\right)$ in this structure is $2.848 \AA$, which is shorter than the $\mathrm{Cu} \cdots \mathrm{C}\left(\mathrm{C}_{60}\right.$ or $\left.\mathrm{C}_{70}\right)$ distances of 2.88 and $2.889(4) \AA$ in CuTPP. $C_{70}{ }^{[8 a]}$ and CuTPP $(\mathrm{Ph})_{4} \cdot \mathrm{C}_{60}{ }^{[8 \mathrm{~d}]}$ respectively, and to the $\mathrm{Zn} \cdots \mathrm{C}\left(\mathrm{C}_{70}\right)$ distance of $2.89 \AA$ in ZnTPP. $\mathrm{C}_{70 .}{ }^{\left[{ }^{[9]}\right.}$

The packing motif of $\mathbf{2}$, looking approximately down the $c$ axis, is shown in Figure 2 b. The crystal structure of $\mathbf{2}$ is a mutually interpenetrating network composed of a pair of 3D frameworks, each of which consists of $2 \mathrm{D}$ structures made of CuTPyP linked with CuAcO units, in which $C_{70}$ are intercalated

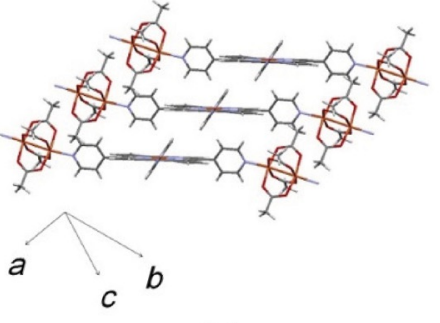

(a)

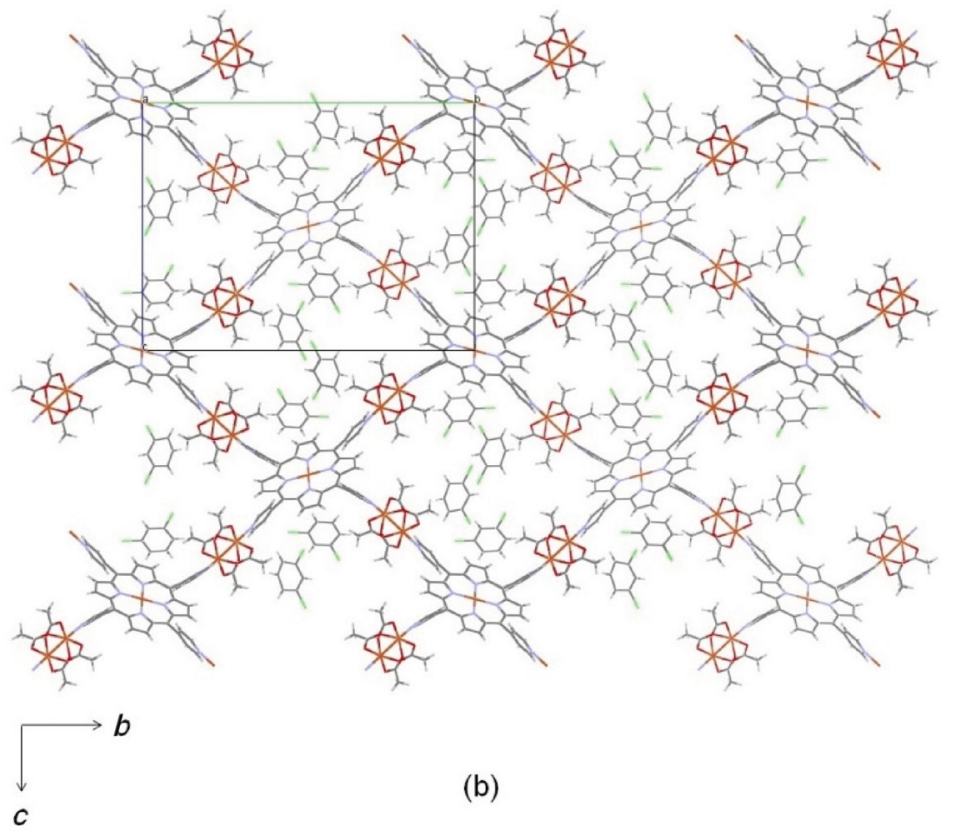

Figure 1. (a) Molecular packing motif of 1. (b) Crystal packing of 1, viewed from approximately down the $a$ axis. Color scheme: $\mathrm{C}=$ gray; $\mathrm{N}=$ blue; $\mathrm{O}=$ red; $\mathrm{Cl}=$ green; $\mathrm{Cu}=$ brown. For clarity, guest molecules were omitted. 

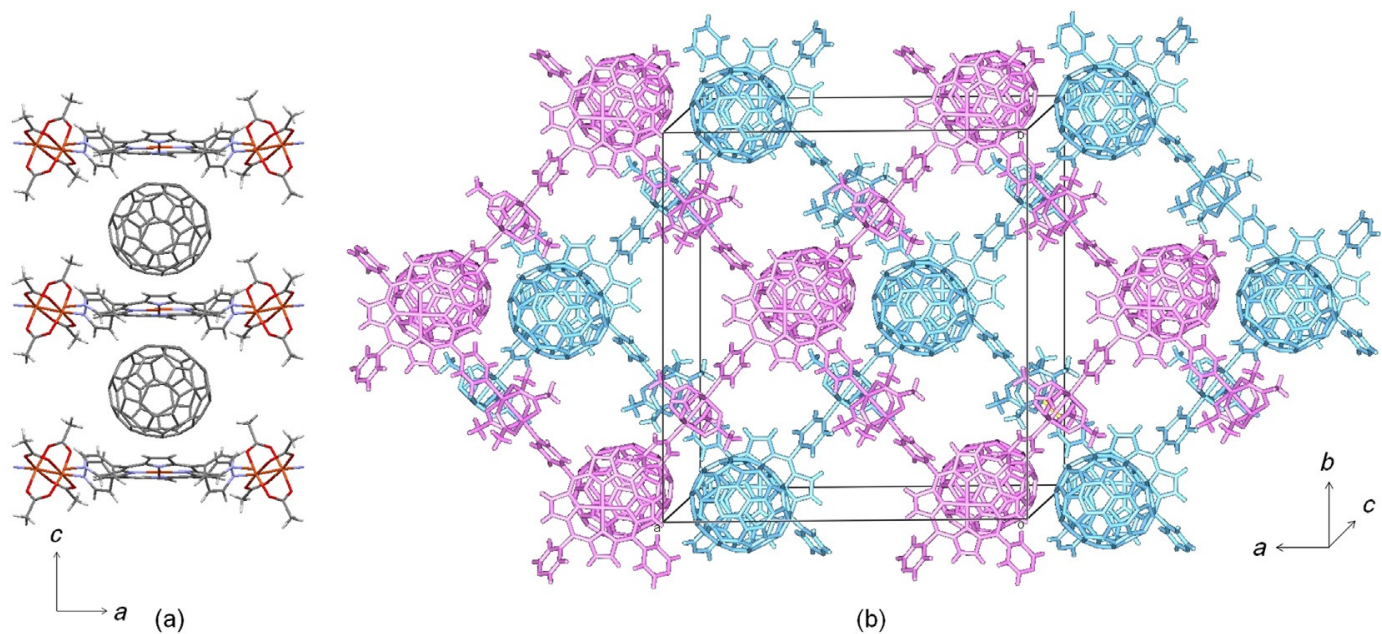

(b)

Figure 2. (a) Details of the noncovalent interactions between CuTPyP and $\mathrm{C}_{70}$ in 2. Color scheme: $\mathrm{C}=\mathrm{gray} ; \mathrm{H}=\mathrm{white} ; \mathrm{N}=\mathrm{blue} ; \mathrm{O}=$ red; $\mathrm{Cu}=$ brown. (b) Two interpenetrating networks (colored separately in sky blue and pink) showing the large void spaces in 2, viewed from approximately down the $c$ axis. For clarity, guest molecules were omitted.

and serve as pillar molecules. In general, interpenetration is more frequently observed when employing larger ligands and/ or pillars. ${ }^{[11]}$ Thus, interpenetration can often be avoided by choosing suitable organic linkers and by controlling the reaction conditions. ${ }^{[12]}$ The free volume of $\mathbf{2}$ is occupied by solvent molecules, but may be estimated from the space left after the $m$-DCB and $\mathrm{CHCl}_{3}$ are released from the 3D network. Despite the interpenetrated structure, there are still large channels running through the sheets, and the estimated free volume is $49.0 \%$. This value is comparable to the $\mathrm{H}_{2}$ TPyP.Pb $\left(\mathrm{NO}_{3}\right)_{2} \cdot \mathrm{C}_{60} \cdot 1.5 \mathrm{TCE} .{ }^{[7 \mathrm{a}]}$ The channel structure of this material is shown in Figure 3. To elucidate the relationship between the stability of this porous structure and guest removal, thermal gravimetric (TG) and thermal desorption mass spectrometry (TD-MS) analyses were carried out (see the Supporting Information). It was anticipated that the removal of guest molecules from 1 and 2 by guest exchange methods would allow these materials to exhibit gas occlusion properties. ${ }^{[13]}$

In this study, a combination of $\mathrm{CuAcO}$ and $\mathrm{H}_{2}$ TPyP displayed impressive molecular separation/isolation capabilities with regard to complexation with fullerenes, preferentially intercalating the larger $C_{70}$ from a $1: 1$ mixture of $C_{60}$ and $C_{70}$. A mDCB solution containing a 1:1 mixture of $C_{60}$ and $C_{70}$ was added to a $\mathrm{CHCl}_{3}$ solution of $\mathrm{H}_{2}$ TPyP, after which a $\mathrm{MeOH}$ solution of CuAcO was also added, followed by stirring for one week. The resulting crystals were filtered, decomposed with $\mathrm{HCl}$, and extracted with $m$-DCB. High-performance liquid chromatography (HPLC) analysis revealed an enriched $C_{70}$ content in these crystals $\left(C_{60} / C_{70}=19: 81\right)$. When a $m$-DCB solution containing a 19:81 mixture of $C_{60}$ and $C_{70}$ was used, the $C_{70}$ was enriched further to a 8:92 $C_{60} / C_{70}$ ratio. The distance of $\mathrm{Cu}$ (CuTPyP)...C( $\left(C_{70}\right)$ in 2 is shorter than the $\mathrm{Cu} \cdots \mathrm{C}\left(\mathrm{C}_{60}\right)$ distances in $\operatorname{CuTPP}(\mathrm{Ph})_{4} \cdot \mathrm{C}_{60} \cdot{ }^{[8 \mathrm{~d}]}$ The selectivity toward higher $\mathrm{C}_{70}$ is dependent on the strong affinity of the $C_{70}$ and CuTPyP. Until now, the separation and isolation of higher order fullerenes has been performed using host-guest complexation. ${ }^{[1]]}$ The MOFs that have been synthesized to date have incorporated ful-

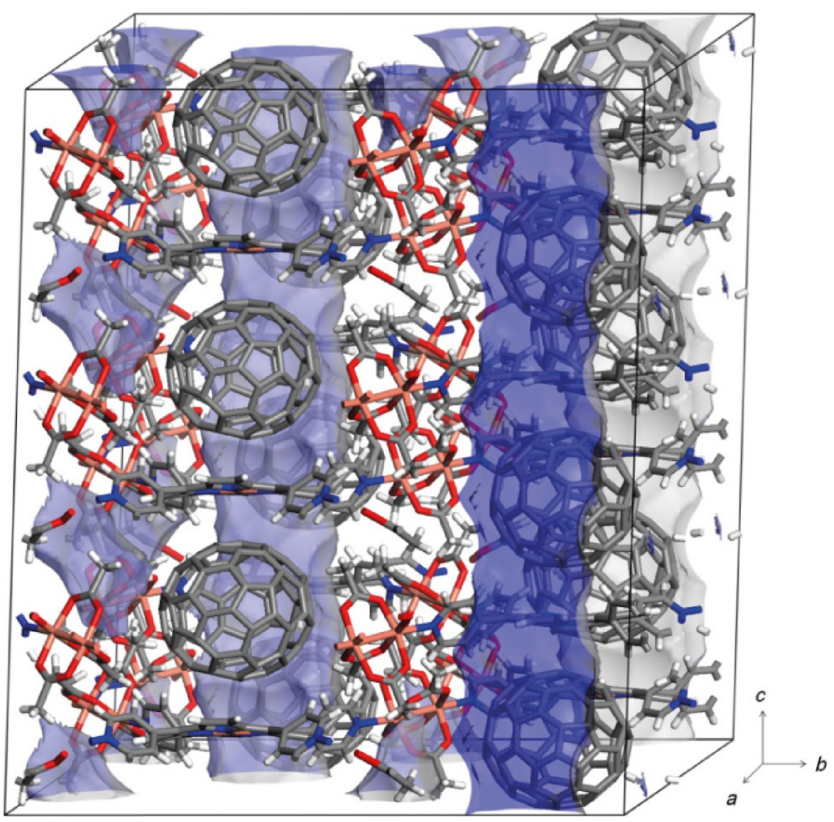

Figure 3. Molecular packing motif of 2, viewed from approximately down the $a$ axis, showing 1-D channels along the $c$ axis. Color scheme: $\mathrm{C}=$ gray; $\mathrm{N}=$ blue; $\mathrm{O}=$ red; $\mathrm{Cl}=$ green; $\mathrm{Cu}=$ brown.

lerenes and, as a result, their internal cavities were eliminated. In contrast, the new P-MOF that we have synthesized in the presence of $C_{70}$ makes it possible to intercalate $C_{70}$ between the porphyrins and thus retain cavities. This phenomenon has not been reported in the past.

In conclusion, we report new porous $2 \mathrm{D}$ and $3 \mathrm{D}$ P-MOF- $\mathrm{C}_{70}$ materials fabricated using CuTPyP units, $\mathrm{Cu}$-based paddlewheel clusters, and $C_{70}$. Applications of these novel P-MOFs include selective sorption of guest molecules and catalysis. We are currently investigating stabilities of P-MOFs by optimizing activation method. This study demonstrates that both P-MOFs and, 
in particular, $\mathrm{P}-\mathrm{MOF}-\mathrm{C}_{70}$ are suitable candidates for the construction of new functional porous structures.

\section{Experimental Section}

$\mathrm{H}_{2}$ TPyP, $\mathrm{C}_{60}$, and $\mathrm{C}_{70}$ were purchased from Sigma-Aldrich, while $\mathrm{CuACO}$ and the solvents (special grade) were purchased from Wako Chemicals (Japan). The single crystal required for XRD analysis was prepared using a diffusion technique at room temperature. To generate 1 , a solution of $C_{60}$ dissolved in $m$-DCB was carefully layered over the top of a solution of $\mathrm{H}_{2}$ TPyP dissolved in $\mathrm{CHCl}_{3}$, after which a solution of $\mathrm{CuAcO}$ dissolved in $\mathrm{MeOH}$ was also layered over top. The resultant mixture was allowed to stand for 2-4 weeks, during which time reddish-brown crystals of the product CuAcO-CuTPyP $\supset m$-DCB (1) were formed without intercalation of $C_{60}$ between the porphyrins. To produce 2 , a solution of $C_{70}$ dissolved in $m$-DCB was carefully layered onto a solution of $\mathrm{H}_{2}$ TPyP dissolved in $\mathrm{CHCl}_{3}$, after which a solution of $\mathrm{CuAcO}$ dissolved in $\mathrm{MeOH}$ was layered over top. The resultant mixture was allowed to stand for 2-4 weeks, during which time dark-brown crystals of the product CuAcO-CuTPyP. $C_{70} \supset m$-DCB.CHCl $(2)$ were formed with $\mathrm{C}_{70}$ intercalated between the porphyrins.

Single-crystal XRD structural data was collected for both $\mathbf{1}$ and $\mathbf{2}$. The crystals were first coated with a light hydrocarbon oil and then mounted on a loop in the nitrogen stream of the diffractometer. Data for complex 1 were acquired using a Rigaku XtaLAB P200 diffractometer with graphite-monochromated $\mathrm{Mo}_{\mathrm{Ka}}(\lambda=0.71075 \AA)$ radiation from a rotating anode source, while data for 2 were collected on a Rigaku Saturn 70 diffractometer with graphite-monochromated $\mathrm{Mo}_{\mathrm{K} \alpha}(\lambda=0.71075 \AA)$ radiation from a rotating anode source. Lorentz and polarization corrections were applied. Check reflections were stable throughout data collection. The structure of 1 was solved by direct methods (SIR2011) ${ }^{[15]}$ with the crystal structure crystallographic software package, and refined by full-matrix least-squares procedures on $F^{2}$ for all reflections (SHELXL2013). ${ }^{[16]}$ The structure of 2 was solved by direct methods (SIR2002) ${ }^{[17]}$ with the crystal structure crystallographic software package and refined by full-matrix least-squares procedures on $F^{2}$ for all reflections (SHELXL-97). ${ }^{[16]}$ The SADI command was applied when modeling the disordered benzene rings of $m$-DCB in $\mathbf{1}$. The $C_{70}$ in $\mathbf{2}$ was modelled as rigid groups using the AFIX and EADP commands. Non-hydrogen atoms were refined anisotropically, while hydrogen atoms were refined using the rigid model. In the case of $\mathbf{1}$ and $\mathbf{2}$, the contribution of the solvent electron density was removed using the SQUEEZE routine in PLATON. ${ }^{[18]}$ The final structures were validated using the PLATON cif check feature. The crystal data and structural refinement details are provided below and in the Supporting Information.

Crystal data for 1 : monoclinic, $P 2_{1} / c, a=7.4591(4), b=29.1282(18)$, $c=21.8936(14) \AA, \beta=96.9878(13)^{\circ}, V=4721.5(5) \AA^{3}, 2 \theta_{\operatorname{Max}}=55.1^{\circ}$, $Z=4$ and $R=0.0417$. Crystal data for 2: monoclinic, $C 2, a=$ 29.992(6), $\quad b=32.852(7), \quad c=12.738(3) \AA, \quad \beta=106.229(3)^{\circ}, \quad V=$ $12051(5) \AA^{3}, 2 \theta_{\text {Max }}=55.0^{\circ}, Z=4$ and $R=0.0844$. CCDC 1451930 (2) and 1451931 (1) contain the supplementary crystallographic data for this paper. These data can be obtained free of charge from The Cambridge Crystallographic Data Centre.

\section{Acknowledgements}

We are grateful to Dr. Kenji Yoza (Bruker AXS K. K.) for helpful discussions concerning the single-crystal X-ray diffraction anal- ysis of $C_{70}$ in 2, as well as to Dr. Akira Shichi (Toyota Central R\&D Laboratories, Inc.) for performing the scanning electron microscopy (SEM) measurements.

Keywords: fullerenes intercalation metal-organic frameworks · porphyrins - supramolecular chemistry

[1] a) W. Mori, T. Sato, C. N. Cato, T. Takei, T. Ohmura, Chem. Rec. 2005, 5, 336-351; b) G. A. Popovich, A. V. Ablov, G. A. Kiosse, I. I. Zheru, J. Struct Chem. 1972, 12, 749-752; c) O. Kristiansson, L.-E. Tergenius, J. Chem. Soc. Dalton Trans. 2001, 1415-1420; d) F. D. Cukiernik, M. I. Elhaj, Z. D. Chaia, J.-C. Marchon, A.-M. G. -Godquin, D. Guillon, A. Skoulios, P. Maldivi, Chem. Mater. 1998, 10, 83-91; e) O. Asai, M. Kishita, M. Kubo, J. Phys. Chem. 1959, 63, 96-99; f) W. Mori, F. Inoue, K. Yoshida, H. Nakayama, S. Takamizawa, M. Kishita, Chem. Lett. 1997, 26, 1219-1220; g) H. Li, M. Eddaoudi, T. L. Groy, O. M. Yaghi, J. Am. Chem. Soc. 1998, 120, $8571-$ 8572 ; h) S. R. Batten, B. F. Hoskins, B. Moubaraki, K. S. Murray, R. Robson, Chem. Commun. 2000, 1095-1096; i) S. S.-Y. Chui, S. M.-F. Lo, J. P. H. Charmant, A. G. Orpen, I. D. Williams, Science 1999, 283, 1148-1150.

[2] a) W. Mori, H. Hoshino, Y. Nishimoto, S. Takamizawa, Chem. Lett. 1999, 28, 331-332; b) R. Nukada, W. Mori, S. Takamizawa, M. Mikuriya, M. Handa, H. Naono, Chem. Lett. 1999, 28, 367-368; c) G. S. Papaefstathiou, L. R. MacGillivray, Angew. Chem. Int. Ed. 2002, 41, 2070-2073; Angew. Chem. 2002, 114, 2174-2177; d) T. J. Prior, D. Bradshaw, S. J. Teat, M. J. Rosseinsky, Chem. Commun. 2003, 500-501; e) D. N. Dybtsev, H. Chun, K. Kim, Angew. Chem. Int. Ed. 2004, 43, 5033-5036; Angew. Chem. 2004, 116, 5143-5146.

[3] a) C. V. K. Sharma, G. A. Broker, J. G. Huddleston, J. W. Baldwin, R. M. Metzger, R. D. Rogers, J. Am. Chem. Soc. 1999, 121, 1137-1144; b) L. Carlucci, G. Ciani, D. M. Proserpio, F. Porta, Angew. Chem. Int. Ed. 2003, 42, 317-322; Angew. Chem. 2003, 115, 331-336; c) L. Carlucci, G. Ciani, D. M. Proserpio, F. Porta, CrystEngComm 2005, 7, 78-86, and references therein; d) T. Ohmura, A. Usuki, K. Fukumori, T. Ohta, M. Ito, K. Tatsumi, Inorg. Chem. 2006, 45, 7988-7990; e) L. D. DeVries, W. Choe, J. Chem. Crystallogr. 2009, 39, 229-240, and references therein; f) R. W. Seidel, I. M. Oppel, Struct. Chem. 2009, 20, 121-128; g) R. W. Seidel, I. M. Oppel, CrystEngComm 2010, 12, $1051-1053$; h) R. W. Seidel, I. M. Oppel, Z. Anorg. Allg. Chem. 2010, 636, 446-448.

[4] S. Matsunaga, N. Endo, W. Mori, Eur. J. Inorg. Chem. 2012, 4885-4897.

[5] M. E. Kosal, J.-H. Chou, S. R. Wilson, K. S. Suslick, Nat. Mater. 2002, 1, $118-121$.

[6] a) M.-H. Xie, X.-L. Yang, C. Zou, C.-D. Wu, Inorg. Chem. 2011, 50, 53185320 ; b) C. Zou, Z. Zhang, X. Xu, Q. Gong, J. Li, C.-D. Wu, J. Am. Chem. Soc. 2012, 134, 87-90.

[7] a) D. Sun, F. S. Tham, C. A. Reed, P. D. W. Boyd, Proc. Natl. Acad. Sci. USA 2002, 99, 5088-5092; b) S. K. Taylor, G. B. Jameson, P. D. W. Boyd, Supramol. Chem. 2005, 17, 543-546.

[8] a) D. V. Konarev, I. S. Neretin, Y. L. Slovokhotov, E. I. Yudanova, N. V. Drichko, Y. M. Shul'ga, B. P. Tarasov, L. L. Gumanov, A. S. Batsanov, J. A. K. Howard, R. N. Lyubovskaya, Chem. Eur. J. 2001, 7, 2605-2616; b) M. M. Olmstead, D. J. Nurco, Cryst. Growth Des. 2006, 6, 109-113; c) A. Hosseini, M. C. Hodgson, F. S. Tham, C. A. Reed, P. D. W. Boyd, Cryst. Growth Des. 2006, 6, 397-403; d) P. Bhyrappa, K. Karunanithi, Inorg. Chem. 2010, 49, 8389-8400; e) P. Bhyrappa, U. K. Sarangi, B. Varghese, Eur. J. Inorg. Chem. 2014, 5646-5650.

[9] P. D. W. Boyd, M. C. Hodgson, C. E. F. Rickard, A. G. Oliver, L. Chaker, P. J. Brothers, R. D. Bolskar, F. S. Tham, C. A. Reed, J. Am. Chem. Soc. 1999, 121, 10487-10495.

[10] a) H. Nobukuni, Y. Shimazaki, F. Tani, Y. Naruta, Angew. Chem. Int. Ed. 2007, 46, 8975-8978; Angew. Chem. 2007, 119, 9133-9136; b) H. Nobukuni, T. Kamimura, H. Uno, Y. Shimazaki, Y. Naruta, F. Tani, Bull. Chem. Soc. Jpn. 2011, 84, $1321-1328$.

[11] a) D. W. Smithenry, S. R. Wilson, K. S. Suslick, Inorg. Chem. 2003, 42, 7719-7721; b) H. Chung, P. M. Barron, R. W. Novotny, H.-T. Son, C. Hu, W. Choe, Cryst. Growth Des. 2009, 9, 3327-3332; c) M.-H. Xie, X.-L. Yang, Y. He, J. Zhang, B. Chen, C.-D. Wu, Chem. Eur. J. 2013, 19, 14316-14321.

[12] a) N. G. Pschirer, D. M. Ciurtin, M. D. Smith, U. H. F. Bunz, H.-C. z. Loye, Angew. Chem. Int. Ed. 2002, 41, 583-585; Angew. Chem. 2002, 114, 603-605; b) C.-C. Tsai, T.-T. Luo, J.-F. Yin, H.-C. Lin, K.-L. Lu, Inorg. Chem. 
2009, 48, 8650-8652; c) A. Aijaz, P. Lama, P. K. Bharadwaj, Inorg. Chem. 2010, 49, 5883-5889.

[13] a) T. K. Prasad, D. H. Hong, M. P. Suh, Chem. Eur. J. 2010, 16, $14043-$ 14050 ; b) S. A. Sapchenko, D. G. Samsonenko, D. N. Dybtsev, M. S. Melgunov, V. P. Fedin, Dalton Trans. 2011, 40, 2196-2203; c) P.-C. Guo, T.-Y Chen, X.-M. Ren, C. Xiao, W. Jin, Dalton Trans. 2014, 43, 6720-6727 d) X.-M. Lin, T.-T. Li, L.-F. Chen, L. Zhang, C.-Y. Su, Dalton Trans. 2012, 41, $10422-10429$

[14] a) J.-Y. Zheng, K. Tashiro, Y. Hirabayashi, K. Kinbara, K. Saigo, T. Aida, S. Sakamoto, K. Yamaguchi, Angew. Chem. Int. Ed. 2001, 40, 1857-1861 Angew. Chem. 2001, 113, 1909-1913; b) Y. Shoji, K. Tashiro, T. Aida, J. Am. Chem. Soc. 2004, 126, 6570-6571; c) E. Huerta, G. A. Metselaar, A Fragoso, E. Santos, C. Bo, J. de Mendoza, Angew. Chem. Int. Ed. 2007, 46, 202-205; Angew. Chem. 2007, 119, 206-209; d) Y. Inokuma, T. Arai, M.
Fujita, Nat. Chem. 2010, 2, 780-783; e) C. Zhang, Q. Wang, H. Long, W. Zhang, J. Am. Chem. Soc. 2011, 133, $20995-21001$.

[15] M. C. Burla, R. Caliandro, M. Camalli, B. Carrozzini, G. L. Cascarano, C. Giacovazzo, M. Mallamo, A. Mazzone, G. Polidori, R. Spagna, J. Appl. Crystallogr. 2012, 45, 357-361.

[16] G. M. Sheldrick, Acta Crystallogr. Sect. A 2008, 64, 112-122.

[17] M. C. Burla, M. Camalli, B. Carrozzini, G. L. Cascarano, C. Giacovazzo, G. Polidori, R. Spagna, J. Appl. Crystallogr. 2003, 36, 1103.

[18] A. L. Spek, J. Appl. Crystallogr. 2003, 36, 7-13.

Manuscript received: January 5, 2016

Accepted Article published: January 15, 2016

Final Article published: February 2, 2016 